\title{
NOTES FOR AUTHORS
}

\section{Submitting a paper}

Full details on submitting a paper, including the style guide and $\mathrm{L}_{\mathrm{A}} \mathrm{T}_{\mathrm{E}} \mathrm{X}$ class file and macro package, can be found at https://www.cambridge.org/core/journals/proceedings-of-the-royal-society-of-edinburgh-sectiona-mathematics/information/instructions-contributors

Proceedings of the Royal Society of Edinburgh: Section A considers for publication papers in all areas of mathematics. Please note that this journal does not consider simultaneous submissions from the same author.

- $\quad$ Authors will be asked to state the primary AMS 2010 Classification Number and between three and six keywords.

- $\quad$ Authors should nominate the most appropriate Editor for their paper.

- It is assumed that the author uploading the paper will be responsible for correspondence. A paper by more than one author should be approved in its entirety by the joint authors. An acknowledgement e-mail will be sent to all authors.

- $\quad$ Proceedings A has a page limit of $25 \mathrm{pp}$ but may consider papers up to five pages longer to allow for variation in final typeset length. Authors must prepare their papers as concisely as possible. Longer papers can be difficult to review in a reasonable time and can be judged more harshly.

- $\quad$ Each paper must be accompanied by an abstract, in general not exceeding 200 words, which will be printed.

- References should be listed at the end of the paper in alphabetical order, numbered sequentially. References within the text should be indicated by numbers in square brackets.

To submit your paper visit https://rse.msp.org/submit_new.php?jpath=rse_proc_a_math and follow the instructions for uploading.

Once a paper has been accepted for publication, authors will be asked to supply the appropriate file. This should be a single file, with any relevant macros included in the preamble, and named after the article reference number (e.g. 150421-authorname.tex). Figures should be submitted as eps or pdf files at the same time as the code for the paper. Detailed instructions will be given on acceptance.

\section{Language}

We recommend that non-English-speaking authors have their manuscripts checked by an English language native speaker before submission, to ensure that submissions are judged exclusively on academic merit. Third-party services specialising in language editing and/or translation can be found here:

https://www.cambridge.org/core/services/authors/language-services. Use of any of these services is voluntary, and at the authors' own expense.

\section{Proofs and offprints}

Authors will be sent proofs of their paper by e-mail in pdf format for checking. A pdf of the final 'publisher's version' of the paper will be sent to the corresponding author shortly after print publication in lieu of hard copy offprints.

\section{Copyright/Open Access}

The RSE now operates a 'hybrid' Open Access model for its journals, for accepted papers submitted on or after 1 April 2013. On acceptance, authors will be given the option of having their paper published either under a regular publication agreement or under a fully Open Access agreement. Under the regular publication option, authors will be asked to sign the Journal's standard transfer of copyright form.

If authors choose the Open Access option, they will be asked to sign the alternative Open Access form and, upon payment of a one-off Article Processing Charge of UK£1780/US\$2835 (in 2017), the final published Version of Record shall be made freely available to all in perpetuity, and will be published under a creative commons licence, enabling its free re-use and re-distribution.

Please note that publication under a fully Open Access agreement is part of the Cambridge Open option. (For more details, please see: https:/www.cambridge.org/core/services/open-access-policies)

Authors are also asked to ensure that any electronic versions of their paper clearly state the official place of publication.

Except as otherwise permitted under the Copyright, Designs and Patents Act, 1988, papers published in Proceedings A may only be reproduced, stored or transmitted with the prior permission of the copyright holder, or, in the case of reprographic reproduction, in accordance with the terms of a licence issued by the Copyright Licensing Agency. The Society permits the making of a single photocopy of an article from an issue (under Sections $29 \& 38$ of the Act) for an individual for the purposes of research or private study.

\section{Websites}

The Royal Society of Edinburgh: www.rse.org.uk

CUP: https://www.cambridge.org/core/ 
(Section A)

\section{CONTENTS}

P.B. ZHANG

Interlacing polynomials and the veronese construction for rational formal power series

A. Gogatishvili and J.S. Neves

Weighted norm inequalities for positive operators restricted on the cone of $\lambda$-quasiconcave functions $17-39$

J.J. BEVAn AND S. KäBISCH

Twists and shear maps in nonlinear elasticity: explicit solutions and vanishing Jacobians

$41-71$

A. Boscaggin, F. Colasuonno and B. Noris

A priori bounds and multiplicity of positive solutions for $p$-Laplacian Neumann problems

with sub-critical growth

73-102

M. Esposito AND M. RuZHANSKy

Pseudo-differential operators with nonlinear quantizing functions

$103-130$

M. Goldman, M. Novaga AND M. RögeR

Quantitative estimates for bending energies and applications to non-local variational problems

$131-169$

T. Dohnal and D. Pelinovsky

Bifurcation of nonlinear bound states in the periodic Gross-Pitaevskii equation with $\mathcal{P} \mathcal{T}$-symmetry

P. TAKÁČ AND J. GIACOMONI

A $p(x)$-Laplacian extension of the Díaz-Saa inequality and some applications

$171-204$

M. PAWELCZYK

Convergence of equilibria for bending-torsion models of rods with inhomogeneities

$205-232$

S. TroscheIT

The quasi-Assouad dimension of stochastically self-similar sets

$233-260$

$261-275$

C. Lois-Prados And R. Rodríguez-López

A generalization of Krasnosel'skii compression fixed point theorem by using star convex sets

$277-303$

M.C. Pereira AND J.D. Rossi

Nonlocal problems in perforated domains

$305-340$

J-B Casteras, E. Heinonen AND I. Holopainen

Existence and non-existence of minimal graphic and $p$-harmonic functions 341-366

M. BREMNER AND V. Dotsenko

Boardman-Vogt tensor products of absolutely free Operads

$367-385$

S. Martínez AND D. Salazar

Multi-clustered solutions for a singularly perturbed forced pendulum equation

$387-417$

F. Giannetti, A. Passarelli di Napoli and C. Scheven

On higher differentiability of solutions of parabolic systems with discontinuous coefficients and $(p, q)$-growth

M.A.D. Aguiar, A.P.S. Dias AND P. SOARES

Characterization of fundamental networks

419-451

$453-474$

B. BARRIOS AND M. MEDINA

Strong maximum principles for fractional elliptic and parabolic problems with mixed boundary conditions

$475-495$

S. HONDA AND M. TAKAHASHI

Evolutes and focal surfaces of framed immersions in the Euclidean space 497-516

P. CORNWELl AND C.K.R.T. JONES

A stability index for travelling waves in activator-inhibitor systems

$517-548$

ISSN 0308-2105

Proc. Roy. Soc. Edinb., A 150

Printed in the UK by Bell \& Bain Ltd

This journal issue has been printed on FSC ${ }^{\mathrm{m}}$-certified paper and cover board. FSC is an independent, nongovernmental, not-for-profit organization established to promote the responsible management of the world's forests. Please see www.fsc.org for information.

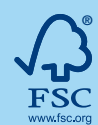

